\title{
Performance Study of Air Driven Engine Being Modified From Conventional Four Stroke Engine without Cam Modification
}

Amit

ABSTRACT: This research presents a novel mechanism to convert a conventional100-cc four stroke driven engine into a 2 stroke compressed air driven engine without doing any modifications in the cam shaft. This allows for a faster valve operation \& also helping the existing engines to be converted into air driven engines with removal of intake and exhaust manifold and also provides a platform to curb the growing menace of air pollution by using the existing old engines to be used as air driven engine. Also, cycle of operation of the Air Engine has been representedon $P-V$ diagram and theoretical efficiency has been calculated which is a function of pressure ratio and temperature, and comes out to be around 80 percent (@ Prr. Ratio of 10\& Temp of 550K). Variation of rpm with percentage valve opening is seen at different pressure ratios and the maximum speed of the engine (after doing said modifications and running through compressed air)is observed to be $1573 \mathrm{rpm}$ at a pressure of 9 bar with the developed mechanism for the existing 4 stroke maestro engine.

\section{INTRODUCTION}

As the world is hard pressed with the energy and fuel crises, compounded by pollution of all kinds, any technologies that bring out the solutions to this problem is considered as a bounty.At first glance the idea of running an engine on air seems to be too good to be true. But in one of such new technologies, is the development of a new engine called as compressed air engine which does not require any of the known fuels like diesel, petrol, CNG, LPG, hydrogen etc. and requires only compressed air as an aid for running the engine [1-2]. This replaces all types of up-to-date known fuels and also permanently solves the problems of pollution as its exhaust is clean and cool measured practically as low as $5^{\circ} \mathrm{C}[3]$. This low temperature air can be used in the air conditioning system of the vehicle directly or by using heat exchanger[4-5]. In present experimental setup at normal pressure, atmospheric temperature of air before compression was $35^{\circ} \mathrm{C}$ and after expansion in the cylinder a dip of $3-4^{\circ} \mathrm{C}$ was observed in the discharge side. Since this engine runs only on high pressure compressed air, the exhaust of which is undoubtedly only air (which is all around us and will never runs out), making it a zero pollution engine[6]. No heat is generated because there is no combustion of fuel, hence this engine needs no cooling system and it result in reduced cost, weight, volume and vibration[7].It requires lighter metal only since it does not have to withstand elevated temperatures. An Air Driven Engine makes use of Compressed Air Technology for its operation[8].

Revised Manuscript Received on December 25, 2020.

* Correspondence Author

Mr. Amit*, Scientific Officer Department of Atomic Energy,Thermal engineering from Delhi

(c) The Authors. Published by Blue Eyes Intelligence Engineering and Sciences Publication (BEIESP). This is an open access article under the CC BY-NC-ND license (http://creativecommons.org/licenses/by-nc-nd/4.0/)
Compressed Air Technology is now widely preferred for research by different industries for developing different drives for different purposes[9]. The Compressed Air Technology is quite simple in principle too. If we compress normal air into a cylinder the air would hold some energy within it. This energy can be utilized for useful purposes. When this compressed air expands, the energy is released to do work.So this energy in compressed air can also be utilized to displace a piston. This is the basic working principle of the Air Driven Engine[10-11]. It uses the expansion of compressed air to drive the pistons of the engine. So an Air Driven Engine is basically a pneumatic actuator that creates useful work by expanding compressed air[12]. This work provided by the air is utilized to supply power to the crankshaft of the engine

\section{NOMENCLATURE}

$\begin{aligned} & T_{1}= \text { Atmospheric Air Temperature } \\ & T_{3}=\text { Air temperature before entering cylinder } \\ & Q_{v d d}=\text { Represents energy inlet to Cylinder (in } \\ & \quad \text { form of compressed air) } \\ & Q_{v e}=\text { Represents energy outlet from Cylinder } \\ & \quad \text { (in form of compressed air) } \\ & \eta=\text { Efficiency } \\ & r_{p}=\text { Pressure Ratio } \\ & C_{p}=\text { Heat Capacity at constant volume } \\ & \gamma \quad=\text { Heat Capacity ratio at constant pressure and volume } \\ & Q_{S}=\text { Heat Supplied } \\ & Q_{R}=\text { Heat Rejected }\end{aligned}$

$R \quad=$ Universal Gas Constant

Published By:

Blue Eyes Intelligence Engineering DOI:10.35940/ijeat B2076.1210220

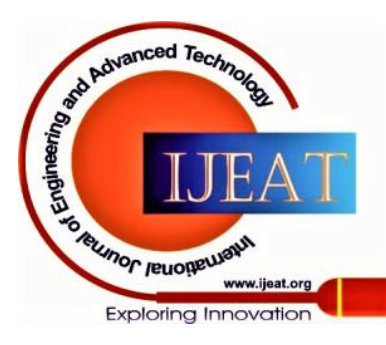


Performance Study of Air Driven Engine Being Modified From Conventional Four Stroke Engine without Cam Modification

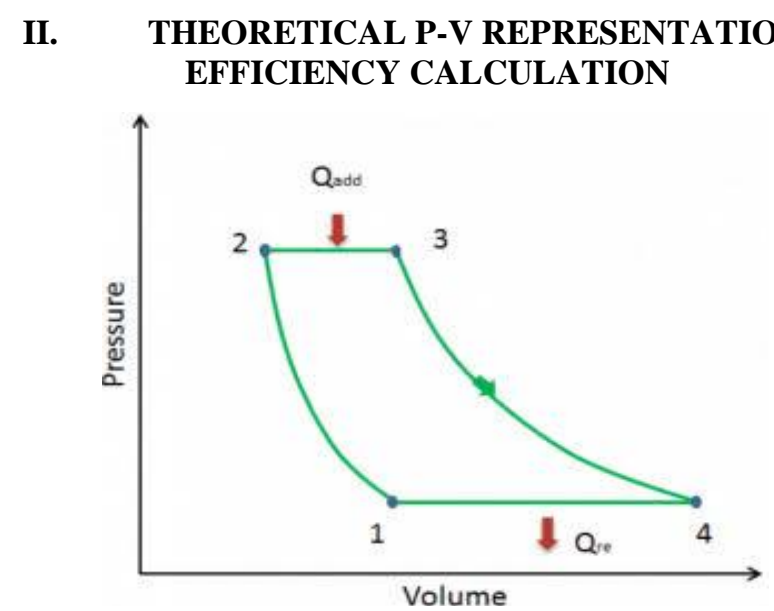

Fig. 1 Theoretical P-V Cycle For CAE

Process 1-2: Isothermal compression

Process 2-3 : Expansion at constant pressure

Process 3-4 : Isentropic expansion inside the engine

Process $4-1$ : Air discharge at constant

pressure from the engine

$\eta=W \cdot D / Q_{s}=Q_{s}-Q_{R} / Q_{S}$
$\eta=1-\mathrm{Q}_{\mathrm{R}} / \mathrm{Q}_{\mathrm{S}}$

$\eta=1-\left[m R \ln \left(\mathrm{P}_{2} / \mathrm{P}_{1}\right)+\mathrm{mC}_{\mathrm{p}}\left(\mathrm{T}_{3}-\mathrm{T}_{2}\right)\right] /\left[\mathrm{mC}_{\mathrm{p}}\left(\mathrm{T}_{4}-\mathrm{T}_{1}\right)\right]$

$\eta=1-\quad\left[m R \ln \left(\mathrm{P}_{2} / \mathrm{P}_{1}\right)\right] /\left[\mathrm{mC}_{\mathrm{p}}\left(\mathrm{T}_{4^{-}} \mathrm{T}_{1}\right)\right]-\left[\mathrm{mC}_{\mathrm{p}}\left(\mathrm{T}_{3}-\mathrm{T}_{2}\right)\right]$ / $\left[\mathrm{mC}_{\mathrm{p}}\left(\mathrm{T}_{4}-\mathrm{T}_{1}\right)\right]$

Now,

So,

$$
C_{P}=\gamma R / \gamma-1
$$

$\eta=1-\left[m R \ln \left(\mathrm{P}_{2} / \mathrm{P}_{1}\right)\right] /\left[\mathrm{m}(\mathrm{rR} / \mathrm{\gamma}-1)\left(\mathrm{T}_{4^{-}}-\mathrm{T}_{1}\right)\right]-\left[\mathrm{mC}_{\mathrm{p}} \mathrm{T}_{2}\left(\mathrm{~T}_{3} / \mathrm{T}_{2^{-}}\right.\right.$

1)] / [ $\left[\mathrm{mC}_{\mathrm{p}} \mathrm{T}_{1}\left(\mathrm{~T}_{4} / \mathrm{T}_{1}-1\right)\right]$

Also,

$\mathrm{T}_{2} / \mathrm{T}_{1}=\left(\mathrm{P}_{2} / \mathrm{P}_{1}\right)^{(\mathrm{\gamma}-1 / \mathrm{\gamma})}=\mathrm{r}_{\mathrm{p}}{ }^{(\gamma-1 / \mathrm{r})}$

And,

So, $\mathrm{T}_{3} / \mathrm{T}_{4}=\mathrm{r}_{\mathrm{p}}^{(\gamma-1 / \gamma)}$

So,

Or, $\mathrm{T}_{2} / \mathrm{T}_{1}=\mathrm{T}_{3} / \mathrm{T}_{4}$

$\mathrm{T}_{4} / \mathrm{T}_{1}=\mathrm{T}_{3} / \mathrm{T}_{2}$

Therefore, $\eta=1-\left[\ln \left(\mathrm{P}_{2} / \mathrm{P}_{1}\right)\right] /\left[(\gamma / \gamma-1)\left(\mathrm{T}_{4}-\mathrm{T}_{1}\right)\right]-\left[\mathrm{T}_{2} / \mathrm{T}_{1}\right]$

$\eta=1-T_{1}\left[\ln \left(r_{p}\right)\right] /\left[(\gamma / \gamma-1)\left(T_{3}-T_{1}\right]-\left[r_{p}^{(\gamma-1 / \gamma)}\right]\right.$

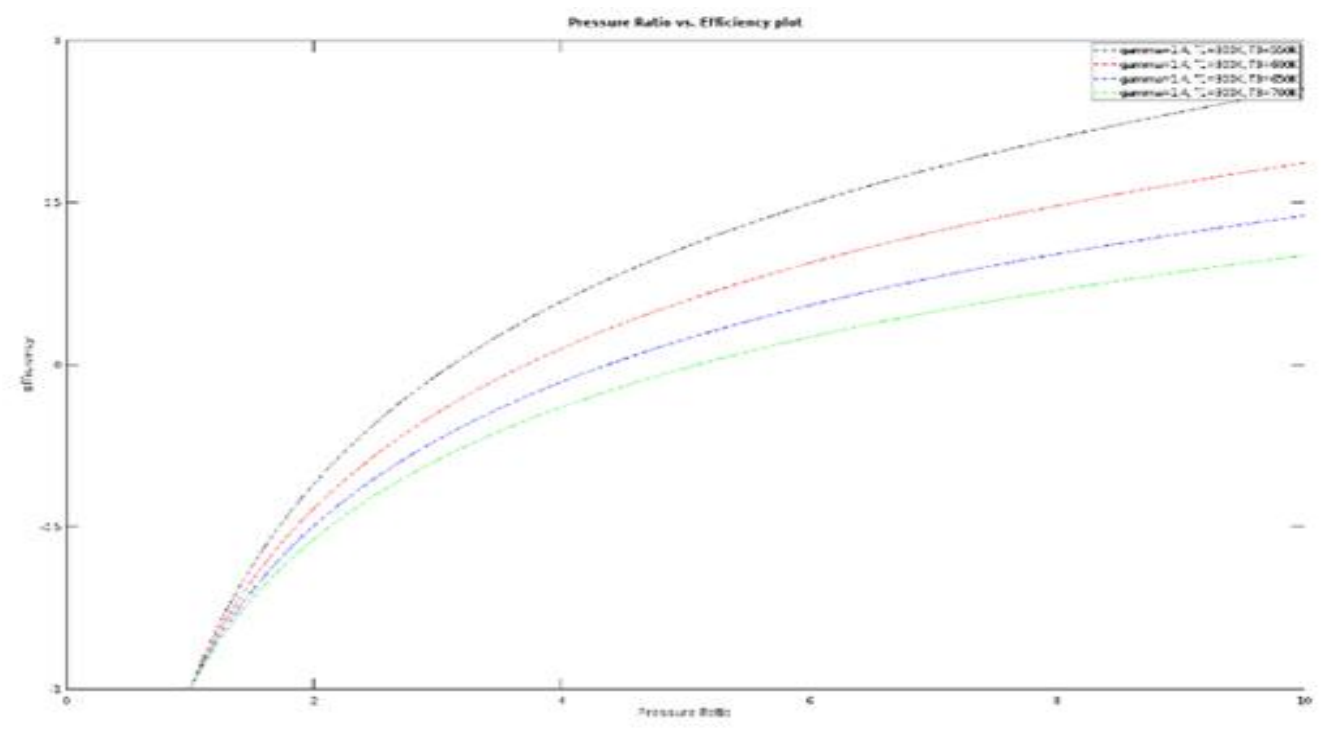

Fig.2Pressure Ratio versus efficiency plot at different temperature

III. EXPERIMENTAL SETUP

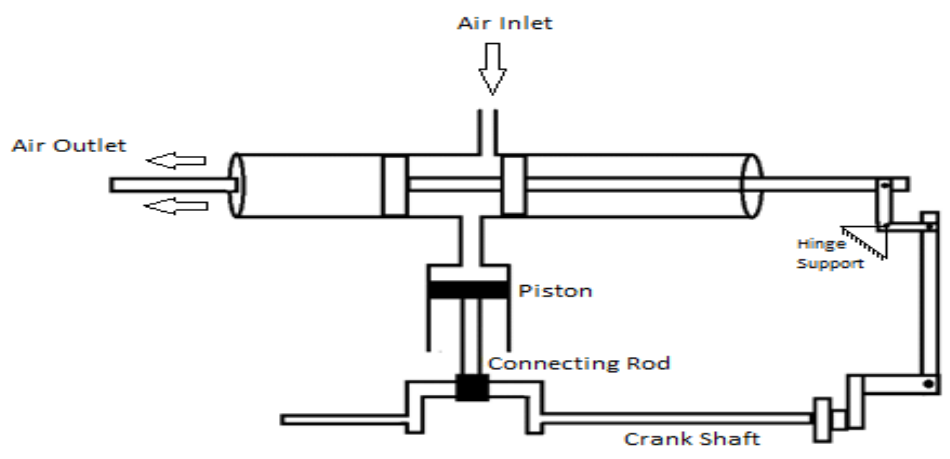

Fig. 3 Mechanism For Converting Four Stroke Engine into Two Stroke Engine

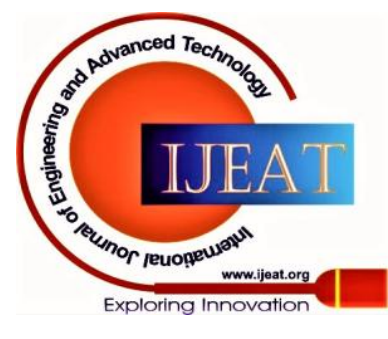


For running a compressed air engine, we require two strokes (one power stroke and the other exhaust stroke). So we require to modify a four stroke engine into a two stroke engine. The modification can be carried out by change in cam profile and gear ratio. But changing the cam profile to desired accuracy is difficult. So the alternate route was developed by working out a mechanism to convert four stroke engine to two stroke. As shown in the figure 3 an offset has been provided to the crank which is further connected with the bell crank lever in order to transmit the rotational movement of the crankshaft into the linear movement of directional control valve to regulate the supply line.

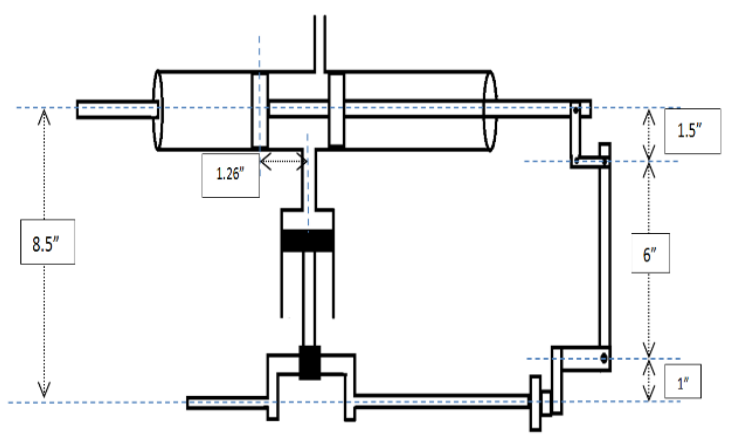

Fig.4 Final optimized dimensions of the engine

Using kinematic and dynamic motion study followed by practical optimization, the final dimensions have been calculated for the mastero four stroke 100cc engine, shown in the figure 4 . In this way, by limiting the distance between the direction control valve pistons and their distance from the piston bore center, we can ensure that the inlet/outlet port will be open to compressed air when piston is at TDC and will be open to exhaust pipe when piston is at BDC which will provide us with 2 stroke functioning of engine.

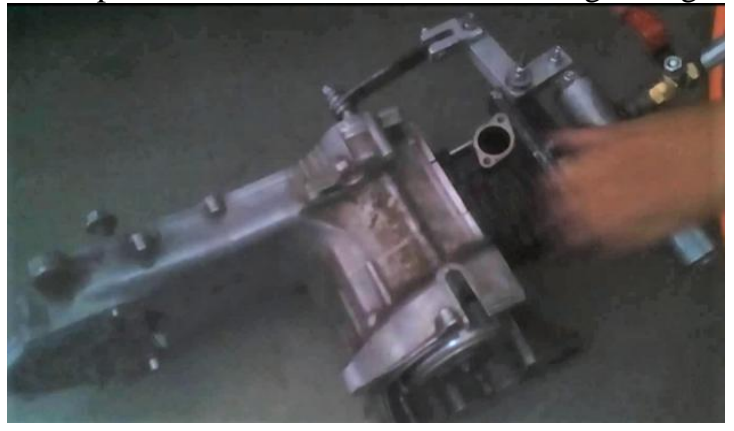

Fig.5Fabricated engine with modified Mechanism

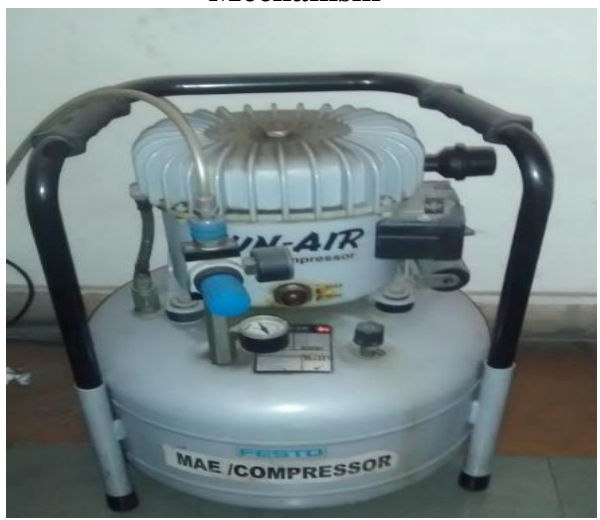

Fig.6 Used Compressor with attached buffer tank

\section{RESULTS}

After doing the said modifications in the engine as shown in Fig 5, it was connected to the air storage (buffer) tank as shown in Fig 6through a ball valve. In the buffer cum storage tank, air was filled from a centrifugal compressor (mounted overhead) having an operating pressure of 100 psi as shown in Fig 6 . The tank has a capacity of 25 litre and got fully charged in approximately 6 minutes and discharged in approximately half minute as shown in Fig 7.

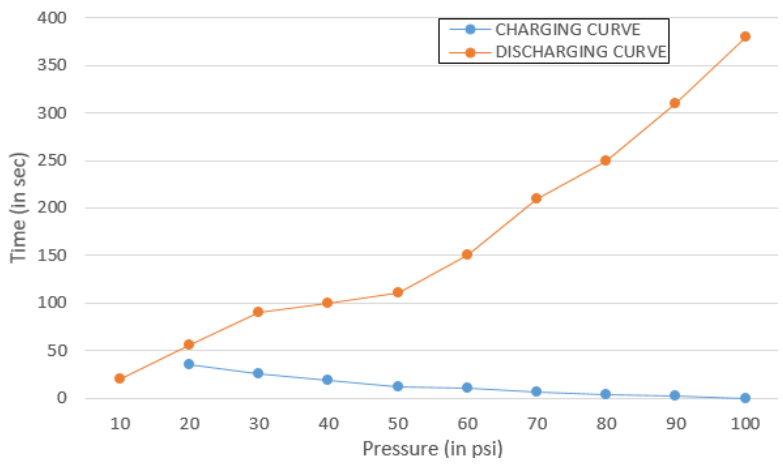

Fig.7 Variation of Charging \& Discharging Time with Pressure in Buffer Tank

Time required for rise/fall of pressure in the tank is less at the beginning and increases at the last because of the fact that initially the difference between inside and outside pressure is more, so the air flow rate is more and hence takes less time when compared with the last stage where the differential pressure with the surrounding becomes very less and hence the flow rate becomes very slow.

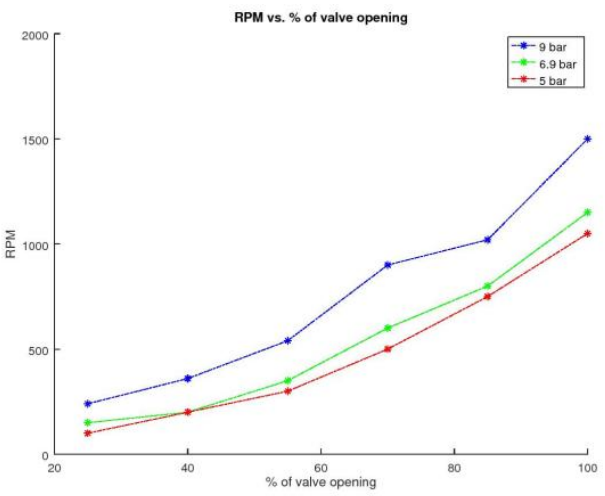

Fig.8 RPM versus \% Valve Opening Variation

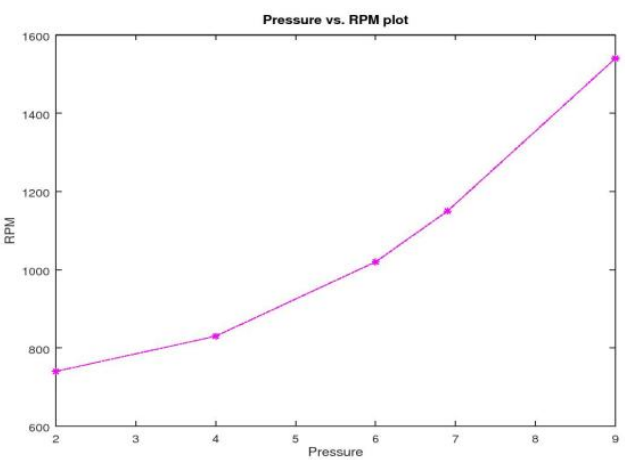

Fig.9 RPM versus Pressure Variation

Published By:

Blue Eyes Intelligence Engineering

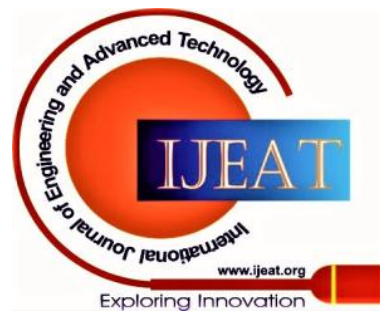




\section{Performance Study of Air Driven Engine Being Modified From Conventional Four Stroke Engine without Cam Modification}

RPM of the crankshaft is found to be a direct function of pressure and valve opening with some parabolic relation as shown inFig 8\&9. With increase of pressure, for a given rpm, efficiency also increases because of the increase of the force over the piston. The curve shown in Fig 10 is plotted using the dynamometer at different loads. When we change the load, rpm of the crankshaft changes, and hence the efficiency of the engine. When we change the load, the torque changes and hence the rpm of the crankshaft which is measured using the tachometer. From the graph shown in Fig 10, it can be seen that the maximum torque is approximately $20 \mathrm{~N}-\mathrm{m}$ and occurs at $500 \mathrm{rpm}$ and shows a decreasing trend after that. The decrease of torque with rpm can be attributed to the fact that the power available is constant. So if one variable increases other must decrease but the decrease is not hyperbolic because of the heat liberated due to friction.
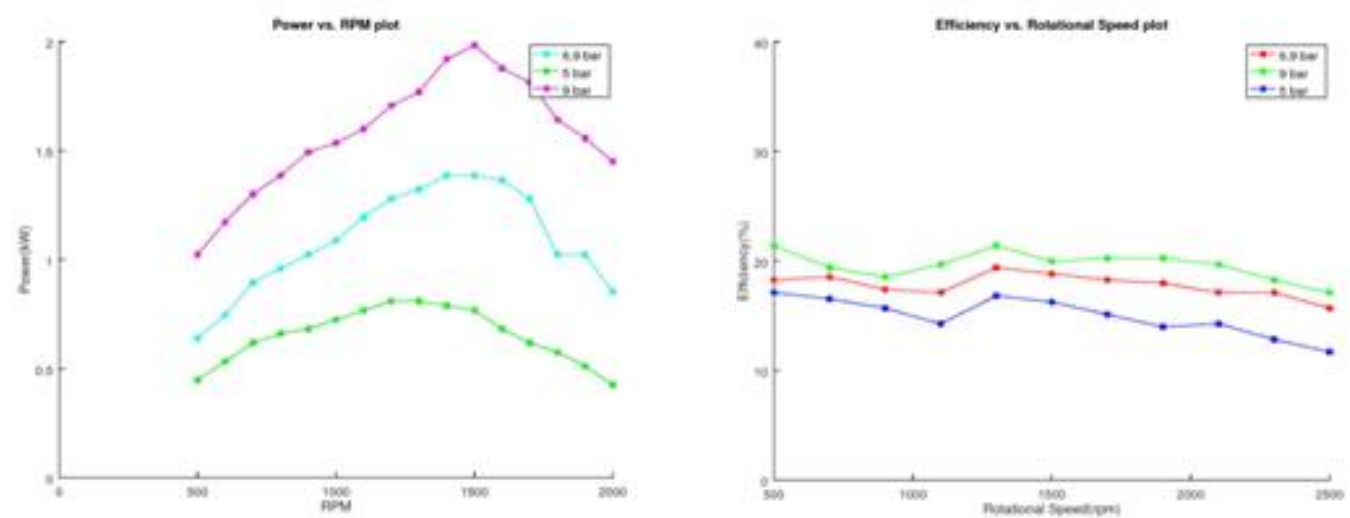

Fig.11Variation of efficiency and power with RPM

Fig 11 showing variation of Power and efficiency with rpm is analytic in nature and is plotted experimentally using the setup. As seen in the curve, power is minimum at the starting and end and rises to a maxima in between.So the importance of this curve is that we will find the rpm corresponding to which the power is maximum and will operate the engine at the same rpm so that we get maximum power output by minimizing the losses.Among the readings taken, we can see that the power is maximum at approximately $1000 \mathrm{rpm}$ when operated at $100 \mathrm{psi}$. Also the maxima shifts towards left side when the pressure is decreased.

\section{CONCLUSION}

In this study, theoretical cycle analysis of air engine on $\mathrm{P}-\mathrm{V}$ Diagram and successful test run have been carried out by modifying a conventional four stroke 100cc engine( without changing cam profile). Thus proving the way for using I.C. Engines as Compressed Air driven Engine on the same assembly line by removing cooling jackets, spark plugs, cylinder head, complex fuel injection systems, silencer and many other parts. With present modifications, a maximum RPM of 1527 was observed at a pressure of 9 Bar. Similarly, the variation of torque and efficiency have also been plotted as a function of rpm and pressure ratio. Overall efficiency of the engine is although not very high because of high inertia forces of the parts designed to operate conventional I.C. Engines, but it can be improved by using light weight material since the load requirements are not high.RPM is

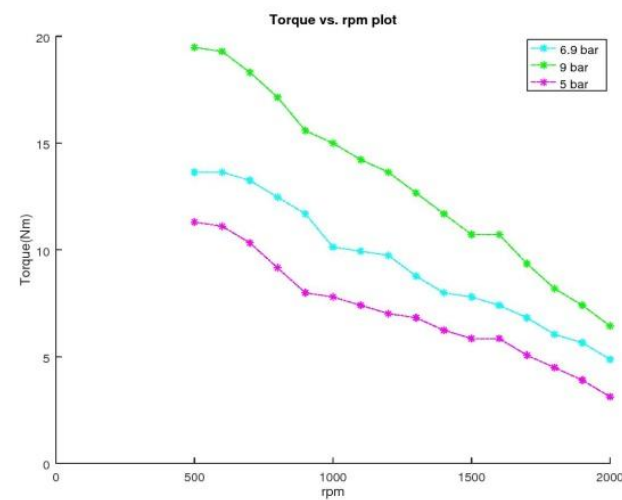

Fig.10 Torque versus rpm Variation energy for conventional working .

\section{ACKNOWLEDGEMENT} for his guidance and support.

\section{REFERENCES} 3.11.2020] WasteManagement Association 51, no. 6 (2001): 809-847.

found to be a direct function of pressure, but going beyond a pressure limit poses its own problem, hence restricting the maximum speed of the engine.The exhaust from the engine is comparatively at a dip of upto $3^{\circ} \mathrm{C}$ with respect to atmosphere because of expansion and can be used in air conditioning system also, thus helping in further improve the efficiency. These types of engine can be used for LMV's and for higher speed and performance, hybrid can prove to be a viableoption specially with gaseous fuels for utilizing the pressure energy in driving the air engine and chemical

The authorwant to thank Mr. Shahbaz Khan in arranging the engine and also for his help during in the erection.The author also want to thank Prof. Rajesh Kumar, Department of Mechanical Engineering, Delhi Technological University

1. https://en.wikipedia.org/wiki/Internal combustion engine[Assessed0

2. Lloyd, Alan C., and Thomas A. Cackette. "Diesel engines: environmental impact and control." Journal of the Air \&

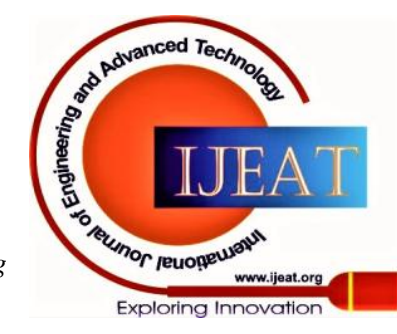


3. Yadav, J. P., and Bharat Raj Singh. "Study and fabrication of compressed air engine." S-JPSET: ISSN 2229 (2011): 7111.

4. Arias, Diego A., Timothy A. Shedd, and Ryan K. Jester. "Theoretical analysis of waste heat recovery from an internal combustion engine in a hybrid vehicle." SAE Transactions (2006): 777-784.

5. Rached, Wissam. "Method for heating and/or air-conditioning in a vehicle." U.S. Patent Application 13/146,721, filed November 24, 2011.

6. Wilson, David Gordon. "Alternative automobile engines." Scientific American 239, no. 1 (1978): 39-49.

7. Ferguson, Colin R., and Allan T. Kirkpatrick. Internal combustion engines: applied thermosciences. John Wiley \& Sons, 2015.

8. Miller, Stewart. "Advanced materials mean advanced engines." Interdisciplinary Science Reviews 21, no. 2 (1996): 117129

9. Mahlia, T. M. I., T. J. Saktisahdan, A. Jannifar, M. H. Hasan, and H. S. C. Matseelar. "A review of available methods and development on energy storage; technology update." Renewable and sustainable energy reviews 33 (2014): 532-545.

10. Budt, Marcus, Daniel Wolf, Roland Span, and Jinyue Yan. "A review on compressed air energy storage: Basic principles, past milestones and recent developments." Applied energy 170 (2016): 250-268.

11. Marvania, Devang, and Sudhakar Subudhi. "A comprehensive review on compressed air powered engine." Renewable and Sustainable Energy Reviews 70 (2017): 1119-1130

12. Deimel, Raphael, and Oliver Brock. "A compliant hand based on a novel pneumatic actuator." In 2013 IEEE International Conference on Robotics and Automation, pp. 2047-2053. IEEE, 2013.

\section{AUTHOR PROFILE}

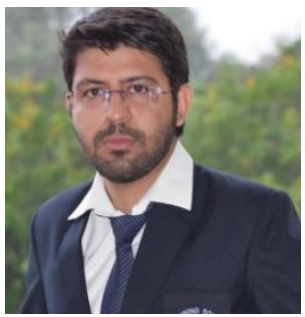

Mr. Amit is presently working as a Scientific Officer in the Department of Atomic Energy. $\mathrm{He}$ is a BARC Training school pass out having an orientation course in Mechanical Engineering with specialization in Design, Operation and maintenance of Nuclear Facilities. He holds an M. Tech in Thermal engineering from Delhi Technological University (Formerly DCE) and has worked on Air Driven Vehicles for his Thesisdefense. His team has represented the college at University level and has won the second price for the same. He is presently working on re-startup of Heavy Water Production facility using Ammonia-Hydrogen Exchange and is also involved in commissioning of Solvent Production Plant for production of vital Solvents to be used in front end and back end of Nuclear Power Plant.

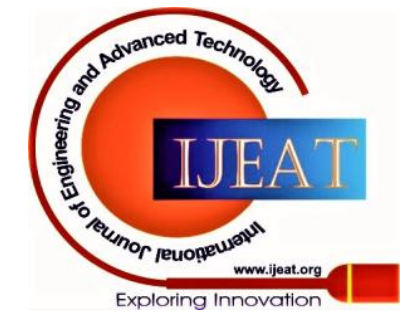

